If Materialism Is True, the United States Is Probably Conscious

Eric Schwitzgebel

Department of Philosophy

University of California at Riverside

Riverside, CA 92521

eschwitz at domain: ucr.edu

September 5, 2012 


\title{
If Materialism Is True, the United States Is Probably Conscious
}

\author{
Abstract: \\ There seems to be no principled reason to deny entityhood to spatially distributed but \\ informationally integrated beings. The United States can be considered as a concrete, spatially \\ distributed but informationally integrated entity. Considered as such, the United States is at least \\ a candidate for the literal possession of real psychological states, including phenomenal \\ consciousness or subjective experience. The question, then, is whether it meets plausible \\ materialistic criteria for consciousness. My suggestion is that if those criteria are liberal enough \\ to include both small mammals and weird alien species that exhibit sophisticated linguistic \\ behavior, then the United States probably does meet those criteria. The United States is \\ massively informationally interconnected and responds in sophisticated, goal-directed ways to its \\ surroundings. Its internal representational states are functionally responsive to its environment \\ and not randomly formed or assigned artificially from outside by the acts of an external user. \\ And the United States exhibits complex linguistic behavior, including issuing self-reports and \\ self-critiques that reveal a highly-developed ability to monitor its evolving internal and external \\ conditions.
}

Keywords: metaphysics, consciousness, phenomenology, group mind, superorganism, collective consciousness, metametaphysics 
[This is only a draft. I welcome feedback. Before citing, please check my website for the latest version.]

\section{If Materialism Is True, the United States Is Probably Conscious}

If materialism is true, the reason you have a stream of conscious experience - the reason there's something it's like to be you while there's (presumably!) nothing it's like to be a toy robot or a bowl of chicken soup, the reason you possess what Anglophone philosophers call phenomenology - is that the material stuff out of which you are made is organized the right way. You might find materialism attractive if you dislike the thought that people are animated by immaterial spirits or possess immaterial properties. ${ }^{1}$

Here's another thought you might dislike: The United States is, literally, like you, phenomenally conscious. That is, the United States, conceived of as a spatially distributed entity with people as (some of) its parts, literally possesses a stream of conscious experience over and above the experiences of its members considered individually. I will argue in this essay that accepting the materialist idea you probably like (if you're a typical early $21^{\text {st }}$ century philosopher) should draw you to accept some group consciousness ideas you probably don't like (if you're a typical early $21^{\text {st }}$ century philosopher) - unless you choose, instead, to accept some other ideas you probably ought to like even less.

The argument in brief is this. If you're a materialist, you probably think that rabbits have conscious experience. And you ought to think that. After all, rabbits are a lot like us, biologically and neurophysiologically. If you're a materialist, you probably also think that conscious experience would be present in a wide range of alien beings behaviorally very similar

\footnotetext{
${ }^{1}$ For purposes of this essay, I'm going to assume that we know, at least roughly, what "material stuff" is. I recognize that this assumption might be problematic. Discussions include Montero 1999; Chomsky 2009; Stoljar 2010.
} 
to us even if they are physiologically very different. And you ought to think that. After all, to deny it seems insupportable Earthly chauvinism; the vast universe (or multiverse) presumably contains many entities that a neutral observer would recognize to be as complex, linguistic, intelligent, and self-aware as we are. It would be odd if among them only we with our neurons had phenomenal consciousness. But, I will argue, a materialist who accepts the possibility of consciousness in oddly-formed aliens ought to accept the possibility of consciousness in spatially distributed group entities. If she then also accepts rabbit consciousness, she ought to accept the possibility of consciousness even in rather dumb group entities. Finally, the United States would seem to be a rather dumb group entity of the relevant sort. (Or maybe, even, it's rather smart, but that's more than I need for my argument.) If we set aside our morphological prejudices against spatially distributed group entities, we can see that the United States has all the types of properties that materialists tend to regard as characteristic of conscious beings.

Of course it's utterly bizarre to suppose that the United States is literally phenomenally conscious. $^{2}$ But how good an objection is that? Elsewhere, I've argued that in metaphysics in

\footnotetext{
${ }^{2}$ The empirical literature on folk opinion about group consciousness is more equivocal than I would have thought, however. See Knobe and Prinz 2008; Sytsma and Machery 2009; Arico 2010; Huebner, Bruno, and Sarkissian 2010; Phelan, Arico, and Nichols forthcoming. Few scholars have clearly endorsed the possibility of literal group consciousness. On group minds without literal consciousness see McDougall 1920; Wilson 2004; and the recent literature on collective intentionality (e.g., Gilbert 1989; Clark 1994; Bratman 1999; Rupert 2005; Tuomela 2007; Searle 2010; List and Pettit 2011; Huebner forthcoming). The reader familiar with the literature on collective intentionality might be predisposed to interpret the arguments and issues of this paper in that light. I think that would be a mistake. My issues and arguments are very different. For example, my focus is entirely on phenomenal consciousness and only derivatively on attitudes; my arguments commit to no claims about the relationships between individual and group attitudes; and I don't claim that group minds are irreducible or that the appeal to a group mind serves any important explanatory purpose.

For more radical views of group minds see Espinas 1877/1924; Schäffle 1875/1896; maybe Wundt 1897/1897; maybe Strawson 1959 (none of whom were materialists). Perhaps the best developed group consciousness view - with some affinities to the present view, though again not materialist - is that of Tielhard de Chardin 1955/1965. See also Lewis \& Viharo's
} 
general and in the metaphysics of mind in particular, it is impossible for a well-developed position entirely to avoid stark violations of common sense - and we ought to expect in any case that common sense would be an untrustworthy guide to metaphysical truth. ${ }^{3}$ Unfortunately, I suggest in that work, once common sense is removed as a trustworthy ground of theory choice, metaphysics reveals itself to be what skeptical outsiders have often thought it was: a bizarre fabric of irresolvable alternatives. It's possible to love metaphysics nonetheless, in a skeptical way. Defense of this general perspective is my background agenda.

My argument is conditional and gappy. If materialism is true, probably the United States is conscious. Alternatively, if materialism is true, the most natural thing to conclude is that the United States is conscious.

\section{Sirian Supersquids, Antarean Antheads, and Your Own Horrible Contiguism.}

We are deeply prejudiced beings. Whites are prejudiced against blacks; Gentiles against Jews; overestimators against underestimators. ${ }^{4}$ Even when we intellectually reject such prejudices, they permeate our behavior and our implicit assumptions. ${ }^{5}$ Were we to meet interplanetary alien travelers similar to us in overall intelligence and moral character, we would likely be prejudiced against them too, especially if their morphology were radically unfamiliar.

"Google Consciousness", TEDxCardiff (June 9, 2011); Vernor Vinge's science fiction portrayal of group minds in Vinge 1992, 2011; Averroës (Ibn Rushd) on the active intellect, 12 ${ }^{\text {th }}$ c./2009; and Edelman 2008, p. 432.

${ }^{3}$ See Gopnik and Schwitzgebel 1998 and especially Schwitzgebel in draft. Some other recent philosophers with doubts about the merits of common sense metaphysics are Churchland 1981; Stich 1983; Kornblith 1998; Dennett 2005; Ladyman and Ross 2007; Mandik and Weisberg 2008; and Weinberg, Gonnerman, Buckner, and Alexander 2010. Hume 1740/1978 and Kant 1781/1787/1998 are also interesting on this issue, of course.

${ }^{4}$ On the last, see Bettencourt, Brewer, Croak, and Miller 1992.

${ }^{5}$ See, for example, the essays collected in Wittenbrink and Schwarz, eds., 2007; Petty, Fazio, and Briñol, eds., 2009. Philosophical discussions include Gendler 2008a-b; Haslanger 2008; Schwitzgebel 2010, 2011. 
It's hard to imagine a prejudice more deeply ingrained than our prejudice against entities that are visibly spatially discontinuous - a prejudice built, perhaps, even into the basic functioning of our visual system. ${ }^{6}$ Analogizing to racism, sexism, and speciesism, let's call such prejudice contiguism.

You might think that so-called contiguism is always justified and thus undeserving of a pejorative label. You might think, for example, that spatial contiguity is a necessary condition of objecthood, so that it makes no more sense to speak of a spatially discontinuous entity than it makes sense - unless you adopt some liberal views about ontology ${ }^{7}$ - to speak of an entity composed of your left shoe, the Eiffel tower, and the rings of Saturn. If you'll excuse me for saying so, that attitude is foolish provincialism. Let me introduce you to two of my favorite nonEarthly species.

The Sirian supersquids. In the oceans of a planet around Sirius lives a naturally-evolved animal with a central head and a thousand tentacles. It's a very smart animal - as smart, as linguistic, as artistic and creative as human beings are, though the superficial form of its language and art is very different from our own. Let's call these animals "supersquids".

The supersquid's brain is not centrally located like our own. Rather, the supersquid brain is distributed mostly among nodes in its thousand tentacles, while its head is home to digestive and reproductive organs and the like. Despite their spatial distribution across its body, however, the supersquid's cognitive processes are fully integrated, and supersquids report having a single, unified stream of conscious experience. Part of what enables their cognitive and phenomenal integration is this: Rather than having relatively slow electrochemical nerves, supersquid nerves

${ }^{6}$ See, for example, Spelke, Brelinger, Macomber, and Jacobson 1992; Scholl 2007; Carey 2009; Burge 2010.

${ }^{7}$ See discussions in Korman 2011; Elder 2011. 
are reflective capillaries carrying light signals, something like Earthly fiber optics. The speed of these signals ensures the tight temporal synchrony of the cognitive activity shooting among the tentacular nodes (and also saves the supersquid precious milliseconds of reaction time to peripheral signals). Three hundred million years ago, the Sirians' home planet had been a giant warehouse for a now-defunct civilization's high-tech optical fiber. The planet was seeded with bacteria that evolved into multicellular organisms, along the way first adapting to incorporate local optical materials and then later manufacturing their own. The supersquids' ancestors congealed as amalgams of simpler organisms most of which became tentacles, unified in their operations by capillaries passing through the central head - though the central head is less cognitively important now, as I will explain shortly.

The supersquids show all external signs of consciousness. They have covertly visited Earth, and one is a linguist who has mastered English well enough to ace the Turing test: He can be (when he wants to) indistinguishable in verbal behavior from a normal adult human being. Like us, the supersquids have communities of philosophers and psychologists who write eloquent books and articles about the metaphysics of consciousness, about emotional phenomenology, about their imagery and dreams. Any unbiased alien observer looking at Earth and looking at the supersquid home planet would see no good grounds for ascribing consciousness to us and denying it to the supersquids. Although certain supersquid philosophers have expressed doubts that Earthly life is capable of genuine phenomenal consciousness, given our radically different physiological structure, I'm glad to say that only a benighted minority of supersquid philosophers hold that view.

Here's another interesting feature of supersquids: They can detach their limbs. Earlier in their evolutionary history, their limbs were permanently attached, as most species' limbs are. 
But light signals can travel through water. The two main things required for a supersquid limb to be separable is that it be able to maintain homeostasis briefly on its own and that suitable lightsignal transceivers appear on the surface of the limb and the bodily surface to which the limb is normally attached. Once the supersquids' ancestors began down this evolutionary path, selective advantages nudged them farther along. Detachable limbs are, among other things, terrific for hunting and for reaching into narrow spaces. Two major subsequent adaptations were these: First, the nerve signals between the head and the limb-surface transceivers shifted to wavelengths less readily occluded by obstacles. And second, the limb-surface transceivers developed the ability to communicate directly between themselves without needing to pass signals through the central head. Since the speed of light is negligible, supersquids can now detach arbitrarily many limbs and send them roving widely across the sea with hardly any disruption of their normal cognitive processing. The energetic costs are high, but the supersquids, being technologically savvy, are able to supplement their diet sufficiently and also to artificially amplify their signals.

In this limb-roving condition the limbs remain constantly under full central (or "central") control; their limbs are not roving independently under local limb-only control, then reporting back. Limb-roving squids remain as cognitively integrated do non-roving squids, and as intimately in control of their entire spatially distributed selves. Despite all the spatial intermixing of their limbs with those of other supersquids, each individual's cognitive processes remain private because each supersquid has a distinctive signature wavelength pattern employed by its transceivers. Furthermore, if a limb is lost, new ones can be artificially grown and fitted, though losing too many limbs at once can result in substantially impaired memory and cognitive function. The supersquids are now starting to experiment with limb exchange, including developing inter-individual compatible transceiver signals. This has led them toward more 
Parfitian views of personal identity than one typically finds in humans, and it has changed their views on the possibilities of marriage, team sports, and scientific collaboration. ${ }^{8}$

I hope you'll agree with me, and with the opinion universal among the supersquids, that supersquids are coherent entities. Despite their spatial discontinuity, they aren't arbitrary collections. They are integrated systems that can be treated, at least for social and cognitive and philosophy-of-mind purposes, as beings of the sort that might house consciousness. And if they might, they do. Or so you should probably say if you're a mainline philosophical materialist. After all, supersquids are naturally evolved beings that act and speak and write and philosophize just like we do.

Does it matter that this is only science fiction? I hope you'll agree that supersquids - or entities relevantly similar, that is, entities having spatially distributed conscious cognition mediated by light waves - are at least physically possible. ${ }^{9}$ And if such entities are physically possible, and if the universe is as large as most contemporary cosmologists think it is - maybe even infinite, maybe even one among an infinite number of infinite universes $!^{10}-$ then it might not be a bad bet that some such spatially distributed intelligences are actual. Biology can be provincial, maybe, but not metaphysics; you'd better have room in your metaphysics for supersquids.

The Antarean antheads. On the surface of a planet around Antares lives a species of animals who look like woolly mammoths but who act much like human beings. I have gazed into my crystal ball and this is what I see: Tomorrow, they visit Earth. They watch our television shows, learn our language, and politely ask permission to tour our lands. It turns out that they

\footnotetext{
${ }^{8}$ These last thoughts are inspired by Parfit 1984 and Churchland 1981.

${ }^{9}$ Sound waves might also work as well or better, as in Vinge 1992, 2011.

${ }^{10}$ See, for example, Greene 2011.
} 
are sanitary, friendly, excellent conversationalists, and well supplied with rare metals for trade, so they are welcomed across the globe. They are quirky in a few ways, however. For example, their cognitive activity takes them, on average, about ten times longer to execute. This has no overall effect on their intelligence - especially since they live a thousand years and in their natural environment face few physical threats requiring swift reaction - but it does test the patience of conversational partners unaccustomed to the Antareans' slow pace. The Antareans also find some tasks cognitively easy that we find cognitively difficult, and vice versa. For example, they are baffled and amused by our difficulty with simple logic problems like the Wason Selection Task (Wason 1968) and tensor calculus, but they are impressed by our skill in integrating auditory and visual information.

Over time, some Antareans migrate permanently down from their orbiting ship. Patchy accommodations are made for their size and speed, and they start to attend our schools and join our corporations. Some achieve political office and display approximately the normal human range of vices. Although Antareans don't reproduce by coitus, they find some forms of physical contact arousing and have broadly human attitudes toward pair-bonding. Marriage equality is achieved. What a model of interplanetary harmony! Ordinary people across the planet all agree, of course, that Antareans are conscious. Did I mention that, like the Sirian supersquids, some of them are very accomplished philosophers of mind and introspective psychologists?

Here's why I call them "antheads": Their heads and humps contain not neurons but rather ten million squirming insects, each a fraction of a millimeter across. Each insect has a complete set of minute sensory organs and a nervous system of its own, and the antheads' behavior arises from complex patterns of interaction among these individually dumb insects. These mammoth creatures are much-evolved descendants of Antarean ant colonies that evolved in symbiosis with 
a brainless, living hive. (The hive itself began its evolutionary history as a simple, non-living physical structure. It slowly incorporated symbiotic organisms - as Earthly ant hives sometimes do - which eventually merged into a unified whole.) The Antareans' giant heads and humps have, altogether, a few orders of magnitude more neuron-like cells then the human brain has, and the insects' interactions are so informationally efficient that neighboring insects can respond differentially to the behavioral or chemical effects of other insects' individual outgoing efferent nerve impulses. The individual ants come in different types varying in size, structure, sensa, and mobility. There are specialist ants with various affinities, antagonisms, and predilections, but no ant individually approaches human intelligence. No individual ant, for example, has an inkling of Shakespeare despite the Antareans' great appreciation of Shakespeare's work.

There seems to be no reason in principle that such an entity couldn't execute any computational function that the human brain could execute or satisfy any high-level functional description that the human organism could satisfy. All the creativity of literary interpretation, all the cleverness of humor and weirdness of visual art, should be available to the antheads on standard materialist approaches to cognition.

Maybe there are little spatial gaps between the ants. Does it matter? Maybe, in the privacy of their homes, the ants sometimes disperse from the body, exiting and entering through the mouth. Does it matter? Maybe if the exterior body is too severely injured, the ants recruit a new body from nutrient tanks - and when they march off to do this, they retain some cognitive coordination, able to remember and report thoughts they had mid-transfer. They reconvene and say, "Oh it's such a free and airy feeling to be without a body! And yet it's a fearful thing too. It's good to feel again the power of limbs and mouth. May this new body last long and well! Shall we dance, then, love?" 
We humans are not so different perhaps. In one perspective (e.g., Maynard Smith and Szathmáry 1995) we ourselves are but symbiotic aggregates of simpler organisms that invested in cooperation and farmed out organismic-level reproductive tasks to a specialized subpopulation.

If you have contiguist prejudices, like I still do, I hope these examples help undercut them somewhat. The natural thing here, I think, is for the materialist simply to agree: Conscious entities need not necessarily be spatially contiguous. This might be so as much in cases that activate our prejudices - cases of entities maybe even not easily understood by us to be entities as it is in cases, like the two above, designed to deactivate our prejudices.

\section{Anti-Nesting Principles.}

You might object to the Antarean antheads even if you're okay with Sirian supersquids. You might think, for example, that the individual ants would be individually conscious and that, for some reason, it's impossible for one conscious organism to be constituted by other conscious organisms. Some theoreticians of consciousness have said such things - though never (that I'm aware of) with what seems to me a good motivation.

Hilary Putnam (1965), for example, stipulates that no organism capable of feeling pain possesses a decomposition into parts which are separately capable of feeling pain. Putnam offers no argument for this stipulation apart from the fact that he wants to rule out the apparently absurd possibility of "swarms of bees as single pain-feelers" (p. 163). He doesn't explain why this possibility is absurd for actual swarms of bees, much less why no possible future evolutionary development of a swarm of conscious bees could ever also be a single pain-feeler. It seems a danglingly unjustified exception to Putnam's otherwise clean functionalism. 
Giulio Tononi (forthcoming) also advances an anti-nesting principle. Tononi suggests that whenever one informationally integrated system is nested in another, consciousness occurs only at the level of the most highly integrated organization. Tononi defends this principle by appeal to Occam's razor, with intuitive support from the apparent absurdity of supposing that a third group consciousness could emerge from two people talking. ${ }^{11}$ But it's unclear why Tononi should put much weight on the intuitive resistance to group consciousness, given his near panpsychism: Tononi defends the idea that a photodiode or an OR-gate could have a single bit's worth of consciousness (Tononi 2004, 2008, 2012; Balduzzi \& Tononi 2009). Why not some such low-level consciousness from the group, too? And Occam's razor is a tricky implement: Although admitting the existence of unnecessary entities seems like a bad idea, what is an "entity" and what is "unnecessary" is often unclear, especially in part-whole cases. Is a hydrogen atom an unnecessary entity once one admits the proton and electron into one's ontology? What makes it necessary, or not, to admit the existence of consciousness in the first place? It is obscure why the necessity of admitting consciousness among the Antarean antheads should turn on whether it is also necessary to admit conscious experience in some of their subparts.

Anti-nesting principles, though seemingly designed to avoid counterintuitive implications of group consciousness, bring different counterintuitive implications in their train. As Ned Block (1978/1991) argues against Putnam, such principles appear to have the unintuitive consequence that if ultra-tiny conscious organisms were somehow to become incorporated into

${ }^{11}$ In an earlier work, Tononi (2010, note 9) discusses an anti-nesting principle without endorsing it. There he states that such a principle is "in line with the intuitions that each of us has a single, sharply demarcated consciousness". In his more recent article, Tononi does not repeat his appeal to that intuition - perhaps thinking that the principle gets stronger support from the Occam's razor argument and intuition against group consciousness. 
your brain - perhaps, for reasons unbeknownst to us, each choosing to play the role of one neuron - you would be rendered nonconscious, despite the fact that all your behavior, including self-reports of consciousness, might remain the same. (On a strong version of the principle, even incorporating one such being might end your consciousness; on weaker versions, perhaps incorporating one such being would be harmless, but having them occupy your whole visual cortex would make you - evidently unbeknownst to yourself - phenomenally blind. ${ }^{12}$ ) Tononi's principle also seems to imply that if there were a large enough election, with enough different ballot measures, with the detailed results communicated back to each voter, the resulting politylevel informational integration would eclipse the informational integration of the main conscious stream in the human brain, thus causing all the individual voters to lose consciousness. ${ }^{13}$ Perhaps we are already on the verge of this in California? Furthermore, since "greater than" is a yes-or-no property rather than a matter of degree, there ought on Tononi's view to be an exact point at which higher-level integration causes our human-level consciousness suddenly to vanish (see esp. his 2010 note 9). There ought to be a point at which the addition of a single voter would cause the loss of consciousness in all other voters - even without any detectable behavioral or self-report effects, or any loss of integration, at the level of individual voters. It seems odd to suppose that so much, and simultaneously so little, could turn on the discovery of a single mail-in ballot.

\footnotetext{
${ }^{12}$ For a related point involving replacement by homunculi or mechanical parts, see Cuda 1985; Chalmers 1996.

${ }^{13}$ In conversation, Tononi has resisted this suggestion, saying that the amount of informational integration in such an election would not be nearly as high as it seems to me it would be, using the entropy formula he provides. It remains unclear to me what might justify Tononi's resistance on this point, especially given his principle that spatial and temporal grain are not intrinsically meaningful but rather should be chosen to maximize the measure of integrated information. (I choose a temporal grain of one day and a spatial grain of one node per voter.)
} 
Exclusionary anti-nesting principles seem to swap one set of counterintuitive implications for another, in the process abandoning general, broadly appealing materialist principles - the sort of principles that suggest that we, the Sirian supersquids, and the Antarean antheads are all on a par given the broad similarities in our behavior, functional sophistication, and evolutionary history.

\section{Dumbing Down.}

If you're a materialist, you probably think rabbits are phenomenally conscious - that is, that "there's something it's like to be" a rabbit, that rabbits experience pain, have visual experiences, and maybe have feelings like fear. They might not have much explicit selfconsciousness; they might not think about their own minds; but they are loci of streams of experience of at least a here-and-now sensory sort. Some philosophers would deny rabbit consciousness; more on that later. For the purposes of this section, I'll assume you're on board. And if you accept rabbit consciousness, you probably ought also to accept the possibility of consciousness in the Sirian and Antarean equivalents of rabbits.

On Sirius, every species in the squid evolutionary class has limb-distributed cognitive processing mediated by light waves through reflective capillaries. Only the supersquids have language and culture of anything like human complexity; the remaining branches of the class are occupied by animals of roughly mammalian intelligence and habits. One such species is the squidbits, a species similar in intelligence and behavior to Earthly rabbits. When chased by predators, Sirian squidbits will sometimes eject all their limbs in a thousand directions and hide their central heads. The predator might then catch a few limbs, but the squidbit survives intact. With the exception of some philosophers and theologians, Sirian supersquids regard squidbits as 
conscious entities. Whatever reasoning justifies attributing consciousness to rabbits similarly justifies attributing consciousness to squidbits.

A similar story holds on Antares: one species of antheads possessing human-like intelligence, while other closely-related species have broadly mammalian intellectual capacities.

Some of the Antarean ant species evolved the capacity to send individual ants out of their bodies to conduct small tasks. A few of these species were so successful in doing so that their bodies lost mobility, and all remote tasks are now conducted by individual ants or groups of ants. The Antarean antheads regard this as a kind of evolutionary regression back to pre-mobility hive forms, and there is dispute about whether their sedentary cousins really have conscious experience. However, I personally side with those Antarean philosophers who think that it is simply prejudice to treat hive mobility as essential to consciousness. Those same Antarean philosophers are inclined to think it is also only prejudice for Earthlings to deny group-level streams of experience to the most sophisticated Earthly social insect species.

Gazing into the distant future on Sirius, I see this: The central body of the squidbit becomes smaller and smaller - thus easier to hide - and the limbs develop more independent sensory and homeostatic nutritional capacities, until the primary function of the central body is reproduction of these increasingly independent limbs. Earthly entomologists come to refer to those heads as "queens". Still later, squidbit queens enter into symbiotic relationships with brainless but mobile hives, and the thousand bits learn to hide within for safety. These mobile hives look something like woolly mammoths. I hope such thought experiments help problematize the distinction between spatially distributed unitary entities and spatially distributed group entities. 
I conclude: Most materialists ought to be willing to countenance the possibility of consciousness in spatially distributed systems of considerably less than human levels of intelligence and self-awareness.

Before we come back to Earth, I want to pause to reflect on the substantial thesis to which I have argued it is natural for the materialist to be committed. It is the thesis that entities radically different from us might be conscious, and that we should probably willing to ascribe consciousness to such radically different entities if they have mammal-like behavioral sophistication and mammal like evolutionary histories. I have justified this claim by thinking about what it would be natural to say about hypothetical cases that would seem to be physically possible or maybe even actual in a large enough universe.

This claim is not quite the same as the claim that linguistic behavioral similarity alone is enough to establish the existence of consciousness (cf. Turing 1950), though it is related. The present claim is stronger in that, by including rabbits, it includes non-linguistic entities. But it is also weaker in that it allows a broader range of criteria than linguistic behavior to count toward the sufficiency claim, including a broad range of animal-like behaviors and the entity's learning and evolutionary history. Thus, I hope the claim can appeal to a broad range of materialist accounts that emphasize the importance of things like naturally-acquired functions.

My claims about Sirians and Antareans might seem to conflict with "type materialist" views that equate human conscious experience with certain specific biological processes. I don't think they do conflict, however. Most type materialist accounts allow that weird alien species might have conscious experiences. Three possibilities compatible with type materialism are: Phenomenal experiences might be identical to different types of physical states in different creatures; physical states might be type-identical across species, at an intermediate level of 
organization, despite very different low-level implementation; or weird creatures might have phenomenology of a very different character from ours corresponding to their very different physical natures. ${ }^{14}$ To assess which hypothetical alien species it is plausible to attribute consciousness to, even on a type-materialist view, it seems natural to consider things like the species' intelligent-seeming behavior and their evolutionary histories - and to be satisfied, I suspect, if one finds broadly mammal-like clades. Philosophical approaches that insist specifically on Earthly biological structures regardless of a species' outward behavior and evolutionary history I discuss under the heading of "neurochauvinism" in Section 7.

You might think that although Earthly rabbits and Sirian squidbits have conscious experience, the only rabbit-intelligence entities that have consciousness are those that are morphologically very similar to entities with the full range of human-like intelligent and linguistic behaviors. But that requirement makes the consciousness of a species oddly extrinsic, dependent on the evolutionary history of clades with which it might be entirely out of contact. Seemingly less oddly, you might think that we should at least refrain from deciding whether it's right to attribute consciousness to a species until we have discovered whether it has humanlyintelligent cousins. This still seems an awkwardly relational move. Why should it matter to our assessment of a species' consciousness whether that species' physical structures are similar to those of another species, assuming we already know all other relevant facts about the morphology, function, history, and behavior of the target species? This move also opens the possibility that we should skeptically refrain from deciding whether the U.S. is conscious under certain hypothetical conditions - for example, if we were to discover evidence that evolutionary

${ }^{14}$ See for example Lewis 1980; Bechtel and Mundale 1999; Polger 2004; Hill 2009. Block 2002 illustrates the skeptical consequences of embracing type identity without committing to some possibility of broadly this sort. 
cousins of ours were playing out a Ringworld-like scenario of the sort described in the next section.

Such a fairly liberal understanding of the types of entities that can be conscious is, I think, the most natural way of developing the materialist worldview. I hope you agree. I will discuss some more conservative options later.

\section{A Telescopic View of the United States.}

A planet-sized alien who squints might see the United States as a single diffuse entity consuming bananas and automobiles, wiring up communications systems, touching the moon, and regulating its smoggy exhalations - an entity that can be evaluated for the presence or absence of consciousness.

You might say: The United States is not a biological organism. It doesn't have a life cycle. It doesn't reproduce. It has no analog of a genetic code that is copied from generation to generation. It is not biologically integrated and homeostatic. Therefore, even accepting the relatively liberal views so far advocated regarding the types of structures that can house consciousness, there are good grounds for resisting the thought that the United States might have a stream of conscious experience. A further step is clearly necessary.

To this thought, I have two replies.

First, why should consciousness require being an organism in the biological sense? Properly-designed androids, brains in vats, and gods are things may not be organisms in the biological sense and yet are sometimes are thought to have consciousness. (We're assuming materialism here, but some materialists do believe in actual or possible gods.) Having distinctive modes of reproduction is often thought to be a central, defining feature of organisms (e.g., J. 
Wilson 1999; R.A. Wilson 2005), but it's unclear why reproductive mode should matter to consciousness. Human beings might vastly extend their lives and cease reproduction, or they might conceivably transform themselves through technology so that any specific condition on having a biological life cycle is dispensed with, while our brains and behavior remain largely the same. Would we no longer be conscious? Being composed out of cells and organs that share genetic material might also be characteristic of an organism, but as with reproduction it is unclear what would justify regarding such composition as essential to mentality, especially once we consider a variety of physically possible non-Earthly creatures.

Second, it's not clear that nations aren't biological organisms. The United States is (after all) composed of cells and organs that share genetic material, to the extent it is composed of people who are composed of cells and organs and who share genetic material. The United States also maintains homeostasis. Farmers grow crops to feed non-farmers, and these nutritional resources are distributed with the help of other people via a network of roads. Groups of people organized as import companies bring food in from the outside environment. Medical specialists help maintain the health of their compatriots. Soldiers defend their compatriots against potential threats. Teachers educate future generations so that important roles can continue to be fulfilled. Home builders, textile manufacturers, telephone companies, mail carriers, rubbish haulers, bankers, all contribute to the stable well-being of the organism. Police reduce between-part aggression that is unhealthy for the entity as a whole. Politicians and bureaucrats work top-down to ensure that certain actions are coordinated, while other types of coordination emerge spontaneously without top-down control, just as in ordinary animals. ${ }^{15}$ Viewed telescopically, the United States is a pretty awesome animal. Now some of the parts of the United States also,

\footnotetext{
${ }^{15}$ See Stock 1993 for a similar perspective presented in lively detail.
} 
individually, are sophisticated and awesome, but that takes nothing away from the awesomeness of U.S. considered as a single integrated entity - no more than we should be less awed by human biology if we were to find that human cells were filled with Planck-scaled mini-societies of angels whose group-level behavior is partly responsible for our cellular processes, or (more realistically) than we should be disappointed by human biology as we discover evidence of our dependence on microscopic symbionts.

Nations also reproduce - not sexually but by fission. The United States and several other countries are fission products of Great Britain. In the 1860's, the United States almost fissioned again. And fissioning nations retain traits of the parent that affect the fitness of future fission products - intergenerationally stable developmental resources, if you will. As in cellular fission, there is a process by which subparts align into different sides and then separate physically and functionally.

I hope you can tolerate one more wild science-fiction thought experiment?

Ringworld, let's suppose, is a vast, habitable surface spanning an entire planetary orbit. ${ }^{16}$ Its ancestor world, much like Earth, was inhabited by a species of intelligent, spatially contiguous organisms aligned into nations. After they constructed Ringworld around a neighboring star, the nations sent colonists. These colonists splintered into separate national groups, no longer controlled from the home planet. For cultural reasons, nations growing on Ringworld tend to fission after reaching populations of a few hundred million; and those that don't fission are outcompeted and conquered by right-sized nations. The Ringworld nations compete aggressively to fill the surface, and immigration between nations is sharply limited.

${ }^{16}$ An example inspired by Larry Niven (1970), but developed a different direction. 
Some nations grow their populations very quickly, fissioning and fissioning again, then competing against their own and other nations' fission products.

Group-level evolutionary pressures on Ringworld favor fast-growing, fast-fissioning nations whose members are more given to self-sacrifice than was customary on the home planet or than is customary on Earth. Eugenic technology also allows these nations to select a few special individuals in each generation as the source of genetic material for the next generation, thus funneling reproduction through a narrow bottleneck. Some of these nations, ultimately the most successful ones, developed protective envelopes against the aggression of other nations. They learned to move these envelopes around the Ringworld surface. The envelopes sprouted appendages. The individuals within the envelopes grew sedentary relative to the moving envelope, developing massive pods of neural tissue communicating by high bandwidth radio signal with other individuals' neural tissue. These enveloped nations communicate verbally with other nations, moving tactically and strategically against each other, developing alliances and enmities, exploiting local resources and playing for distant resources. Maybe this envelope-level behavior emerges dynamically from the system as a whole, not easily explicable or comprehensible at the level of individual citizens. Maybe individual citizens start to become specialized and dumb.

Presumably, we can tweak this case far enough along the slippery slope to Antares that if we accept anthead consciousness, we should also accept Ringworld enveloped-nation consciousness. The question then becomes at what point along this slope does group-level consciousness arise? And might the United States already be there? On Earth, at all levels, from the molecular to the neural to the societal, there's a vast array of competitive and cooperative pressures; at all levels, there's a wide range of actual and possible modes of reproduction, direct 
and indirect; and all levels show manifold forms of symbiosis, parasitism, partial integration, agonism, and antagonism. ${ }^{17}$ There isn't as radical a difference in kind as people are inclined to think between our favorite level of organization and higher and lower levels.

To be clear: I have not argued (yet) that the United States is conscious - just that it can coherently be evaluated for the presence or absence of group-level consciousness. Suppose our planet-sized alien who squints has just returned from an observational stint at Ringworld. Looking down at us from her telescopic vantage, she might be inclined to think of individual human beings as individually conscious cells in a somewhat vague-boundaried, approximately continent-sized, potentially conscious entity that might not be fully congealed. Maybe she will decide, on further evaluation, that this giant organism or thing-on-the-edge-of-being-a-giantorganism is not yet integrated enough to have nation-level consciousness, or not intelligent enough, or something. Or maybe she will decide that the United States does indeed meet the criteria for consciousness. Either way, the question makes sense to her - and properly so. It's not an absurdity.

\section{What Is So Special About Brains?}

According to materialism, what's really special about us is our brains. Brains are what make us conscious. Maybe brains have this power on their own, so that even a lone brain in an otherwise empty universe would have conscious experience if it were structured in the right way; or maybe our consciousness issues not strictly from the brain itself but rather from a thoroughly entangled mix of brain, body, and environment (e.g., Hurley 1998; Noë 2004; Wilson 2004; Rockwell 2005). But all materialists agree: Brains are awesome!

${ }^{17}$ See for example Maynard Smith and Szathmáry 1995; Sober and D.S. Wilson 1998; R.A. Wilson 2005; Godfrey-Smith 2009. 
Now what is so special about brains, on the materialist view? Why do they give rise to conscious experience while a similar mixture of elements in chicken soup does not? It must be something about how those elements are organized. Two general features of brain organization stand out: their complex high order / low entropy information processing, and their role in coordinating sophisticated responsiveness to environmental stimuli. These two features are of course related. Brains also arise from an evolutionary and developmental history, within an environmental context, which may play a constitutive (and not merely a causal) role in determining function and cognitive content (Putnam 1975; Burge 1979; Millikan 1984; Davidson 1987; Dretske 1988, 1995; Wilson 2004). According to a broad class of plausible materialist views, any system with sophisticated enough information processing and environmental responsiveness, and perhaps the right kind of historical and environmental embedding, should have conscious experience. My central claim is: The United States seems to have what it takes, if standard materialist criteria are straightforwardly applied without post-hoc noodling. It is mainly unjustified morphological prejudice that blinds us to this.

Consider, first, the sheer quantity of information transfer among members of the United States. The human brain contains about $10^{11}$ neurons exchanging information through an average of about $10^{3}$ connections per neuron, firing at peak rates of once every several milliseconds. The United States, in comparison, contains only about $3 \times 10^{8}$ people. But those people exchange a lot of information. How much? One might begin by considering how much information flows from one person to another via stimulation of the retina. The human eye contains about $10^{8}$ photoreceptor cells. Most people in the United States spend most of their time in visual environments that are largely created by the actions of people (including their own past selves). If we count even 1/300 of this visual neuronal stimulation as involving the relevant 
sort of person-to-person information exchange, then the quantity of visual connectedness between people is similar to the neuronal connectedness within the human brain $\left(10^{14}\right.$ connections). Very little of this visual connectedness is verbal, of course, but neither do neurons literally talk to each other. Very little of the exchanged information will make it past attentional filters for substantial further processing, but analogous considerations apply to information exchange among neurons. Visual information transfer between people often works at a delay the email message composed an hour ago influences me now, the menu bar designed three years ago still tells me where to click, the tile pattern chosen for my office floor in 1995 still sometimes calls my attention. But these delays are a feature, not a bug; the brain has to work hard to make information effective persistently and at a delay when it might most be needed. If we insist on real-time exchange, though, we can probably still get about the right order of magnitude looking only at retinal stimulations by light that has been reflected directly off other people's bodies. And also of course there's auditory information exchange between people, which is often more explicitly communicative, with the details of prosody in particular involving high informational bandwidth.

Here's another way to think about the issue: If at any one time $1 / 300^{\text {th }}$ of the U.S. population is viewing internet video at 1 megabit per second, that's a transfer rate between people of $10^{12}$ bits per second in this one minor activity alone - an activity detectably informationally impoverished compared to live communication at normal speaking distance. Cisco Corporation (2012) estimates total global Internet Protocol traffic in 2011 at about $2 \times 10^{19}$ bytes per month, which is about $6 \times 10^{13}$ bits per second for just this one form of human communication. Martin Hilbert and Priscila López (2011) make a similar estimate for total global internet communication in 2007. Recent estimates of the computational capacity of the 
human brain are comparable, running from about $10^{14}$ to $10^{17}$ instructions per second (Moravec 1997; Kurzweil 2005; Hilbert and López 2011). So internet connectedness alone puts us in the ballpark.

But even if these estimates are off by a few orders of magnitude, that doesn't matter much for my general argument. For one thing, it doesn't seem likely that conscious experience requires achieving the degree of informational connectedness of the entire neuronal structure of the human brain. If mice have conscious experience, as most people seem to think - if there's something it's like to be a mouse - they manage to achieve it with under $10^{8}$ neurons. If necessary, too, we could shift example and reconsider the case with a not-too-remote hypothetical. We could push forward a decade or two, imagining rather more sensory and digital information transfer among the populace as communication technology improves. If quantity of information transfer were all that mattered, it seems that we should accept that the United States either is presently conscious or could easily become conscious with a few changes.

A more likely source of concern, it seems to me, is that the information exchange among members of the U.S. population isn't of the right type to engender a genuine stream of phenomenally conscious experience. A simple computer download, even if it somehow managed to involve $10^{17}$ bits per second or more, presumably wouldn't by itself alone do the job. For consciousness, there presumably needs to be some organization of the information in the service of coordinated, goal-directed responsiveness; and maybe, too, there needs to be some sort of ability of the system to monitor itself in a sophisticated way.

But the United States has these properties too. Our information exchange is not in the form of a simply-structured massive internet download. The United States is a goal-directed entity, flexibly self-protecting and self-presenting. The United States responds, intelligently or 
semi-intelligently, to opportunities and threats - not less intelligently, I think, than a small mammal. The United States expanded west as its population grew, developing mines and farmland in traditionally Native American territory. When Al Qaeda struck New York, the United States responded in a variety of ways, formally and informally, in many branches and levels of government and in the populace as a whole. Saddam Hussein shook his sword and the United States invaded Iraq. The U.S. acts in part through its army, and the army's movements involve perceptual or quasi-perceptual responses to inputs: The army moves around the mountain, doesn't crash into it. Similarly, the spy networks of the CIA detected the location of Osama bin Laden, whom the U.S. then killed. Is there less information, less coordination, less intelligence than in a hamster? The Pentagon monitors the actions of the Army, and its own actions. The Census Bureau counts us. The State Department announces the U.S. position on foreign affairs. The Congress passes a resolution declaring that we hate tyranny and love apple pie. This is self-representation. Isn't it?

I am inviting you to conceptualize the United States as our planet-sized alien might - to evaluate the capacities and behaviors of the United States, conceived of as a concrete, spatially distributed entity with people as some or all of its parts - that is, as an entity within which citizens and residents play roles somewhat analogous to the roles that individual cells play in your own body. If you are willing to jettison contiguism and other morphological prejudices, this is not, I think, an intolerably radical perspective.

This body does a lot of sophisticated stuff. It interacts with the environment and with itself in all kinds of complex, self-regulating informational loops, including loops that take advantage of all the sophisticated sub-loops that can occur within individual human brains, and within small and medium-sized and large groups of individual human beings, and through all of 
our technological artifacts. As a house for consciousness, a rabbit brain is not clearly more sophisticated.

Members of the United States differ in their opinions and preferred actions, of course. But the opinions and preferences of individuals are not the opinions and preferences of the United States. The neurons in your visual cortex don't have entirely consistent representational contents either, and the neurons in your motor cortex don't always vote for the same movement. In both the human brain and the United States there is a dynamics of compromise that somehow issues in approximately coherent behavior by the system as a whole. There might even be cases in which the attitudes and emotions of the United States differ from the attitudes and emotions of all or most of its members. The United States might be angry about something, as reflected in group-level punitive behavior and the pronouncements of individuals acting as spokespeople, even if no individual person in the United States feels angry about that thing. The United States might endorse a set of attitudes as its official policy, and consistently act in accord with those attitudes, even if no member of the United States individually endorses that same set of attitudes. ${ }^{18}$ The United States might execute racist policies even if most of its members aren't racist, or it might execute egalitarian policies even if most of its members are racist. The United States might respond intelligently to changes in corporate governance laws in other countries in ways that are unrecognizable to any individual member of the United States. The attitudes, representations, goals, and moods of the U.S. might sometimes involve a relative simple summing of or competition between the attitudes, representations, goals, and moods of its individual members, and at other times they might bear only a very complex relationship to what

${ }^{18}$ See List and Pettit 2011 and other work cited in note 2. As mentioned in note 2, however, I conceptualize my arguments and issues as rather different from the arguments and issues in the mainstream group attitudes literature. 
is going on in individual members and operate strategically quite beyond their ken. Similarly, the relationship, in the human brain, between individual neurons' representational or other functions and the states of the person as a whole is also sometimes simple, sometimes complex. The United States has long been embedded in a natural and social environment, richly causally connected to the world beyond, connected in a way that would seem to give meaning to its representations and functional duties to its parts. It's no randomly congealed "Swampman" that lacks a content-giving history (Davidson 1987; Dretske 1995; Millikan 2010). The United States interacts cooperatively and competitively with other beings of its kind. It wars against Germany, then reconciles, then wars again. It threatens Iran. It cooperates with other countries in threatening Iran. The United States monitors space for asteroids that threaten Earth and would respond if one were detected, perhaps cooperatively with other nations. The United States tracks climate change and ozone levels and takes muted action.

The United States has internal states that play sophisticated functional roles in guiding its behavior. When the spy camera generates an image of bin Laden's compound, that triggers internal states in people who are parts of the United States. Those internal states then connect with other internal states which connect in turn with other internal states, some within people and some between people, generating further reactions, including possibly calling in the strike team. This functional organization can be incredibly fancy. The spy camera image will also generate functional states in computers and photographic plates. We might or might not wish to consider such artifacts as part of the body of the United States. If they are part of the body, they contribute substantially to the complexity of its internal functional dynamics; if not, they contribute substantially to the complexity of the functional dynamics between the United States and the external world. The United States imports oil from countries A and B rather than 
countries $\mathrm{C}$ and $\mathrm{D}$, in response to changes in represented price, and is ready to flip when the represented price changes. Of course, it is always individual people, organized in groups, who together import the oil. It is also individual cells in your brain, organized in groups, and embedded in a larger environment, that together issue the efferent nerve signals, that together respond to the tilting angle of the stimulus, that together match the incoming signal with the stored representation of grandma's face. Great things emerge from contextually embedded groups.

Maybe the actions, attitudes, and representations of the United States are ultimately reducible to the actions, attitudes, and representations of U.S. citizens and residents, in some complex combination. On that issue I take no stand. (What does "reducible" mean?) All that is necessary for this part of my argument is that the United States actually engages in actions, adopts attitudes, and formulates representations, whether reducibly or not, of at least a mammalian level of sophistication. Perhaps, too, all your actions, attitudes, and representations are in some sense reducible to other things; few philosophers conclude that this makes them unreal. Maybe we don't need to appeal to group-level processes to explain, say, the invasion of Iraq. Maybe we can tell the whole story adequately enough by appeal to the actions of lots of single individuals. Or maybe a proper explanation must go to the group level, after all. My argument is silent on these points. My argument does not turn on irreducibility or explanatory necessity. Rather, my thought is this: There's something awesomely special about brains such that they give rise to consciousness, and the United States seems to be awesomely special in just the same sorts of ways.

One might object that "the United States" is an abstraction, like "the average Californian" or "the teenage mind". The average Californian may be conscious, and the teenage mind may 
seethe with angst, but it would be an absurd category mistake to suppose that therefore there exists some additional stream of consciousness of the average Californian beyond the streams of consciousness of each Californian considered individually, or some further bit of angst in addition to all the individual angst of particular teenagers. This objection, however, forgets the concreteness on which I have repeatedly insisted. I am willing to be somewhat flexible about the best way, exactly, to conceptualize the boundaries of the body of the United States (are the roads included? ex-pat citizens?), but I insist that we consider the matter concretely, as does our planetsized alien observer. It is not like seeing all the buildings around campus and then seeking some additional ghostly building which is "the university" (Ryle 1949). Rather, it's like seeing all the buildings around campus and then wondering what features, like open space between the buildings, might be possessed by the campus as a whole but neglected by someone with too narrow a focus on the individual parts.

What is it about brains, as hunks of matter, and brain states, as states of hunks of matter, that makes them special enough to give rise to consciousness? Looking in broad strokes at the types of things materialists tend to say in answer - things like sophisticated information processing and flexible, goal-directed environmental responsiveness, things like representation, self-representation, multiply-ordered layers of self-monitoring and informational-seeking selfregulation, rich functional roles, and a content-giving historical embeddedness - it seems like the United States has all those same features. In fact, it seems to have them in a greater degree than do some beings, like rabbits, that we ordinarily regard as conscious.

What could be missing?

\section{What Could Be Missing.}


Here I would have liked to apply particular, detailed materialist metaphysical theories to the question at hand. I face, however, obstacles that seem to me practically insurmountable. First: Almost no materialist theoretician explicitly considers the possibility of literal group consciousness. ${ }^{19}$ Thus, it's a matter of speculation how properly to apply their theory to a case they may have neglected in their theory's design. Second: Many theories, especially those constructed by neuroscientists and psychologists, implicitly or explicitly limit themselves to human or at least vertebrate consciousness, and thus are silent about how consciousness would work in other sorts of entities (e.g., Baars 1988; Crick 1994). Third: Further limiting the pool of relevant theories is the fact that few thinkers really engage the metaphysics from top to bottom. For example, most theoreticians endorsing "higher order" models of consciousness don't provide enough detail on the nature of the "lower order" mental states for me to evaluate whether the United States would qualify as having such lower-order states (though if it does, it would probably have the higher-order states too). ${ }^{20}$ Fourth and finally: When I arrived at what I thought would be a representative sample of four prominent metaphysically ambitious top-tobottom theories of consciousness, the task of presenting each view in enough detail to explore how it would plausibly apply to this new range of cases proved too complex to embed in an already long essay. ${ }^{21}$ Thus, I think further progress on this issue will require having some

\footnotetext{
${ }^{19}$ Two notable exceptions are Robert A. Wilson (2004) and Bryce Huebner (forthcoming). Huebner seems open to the possibility of group consciousness while refraining from fully endorsing it. Wilson I am inclined to read as rejecting group-level consciousness on the assumption that it has been only sparsely and confusedly advocated, with no advocate meeting a reasonable burden of proof.

${ }^{20}$ For a review of higher-order theories, see Carruthers 2001/2011.

${ }^{21}$ The theories I chose were Dretske's, Dennett's, Humphrey's, and Tononi's. You can see some of my preliminary efforts in blog posts Schwitzgebel 2012a-e. On the most natural interpretations of these four test-case views, I thought that readers sympathetic with any of these authors' general perspectives ought to accept that the United States is conscious. And I confess that I still do think that, despite protests from Dretske, Dennett, Humphrey, and Tononi
} 
concrete counterproposals to evaluate. In this section, I will address three objections, one inferred from remarks by Chris Eliasmith and Andy Clark on the extended mind hypothesis and two derived from email correspondence with prominent materialist theoreticians. In the next section, I will explore three other ways of escaping my conclusion - ways that involve rejecting either rabbit consciousness, alien consciousness, or both.

Chris Eliasmith (2009) and Andy Clark (2009) have recently argued that consciousness requires high bandwidth neural synchrony - a type of informational synchrony that is not possible between the external environment and structures interior to the human brain. Thus, they say, consciousness stays in the head. Now in the human case, and generally in the case of Earthly animals with central nervous systems, perhaps Eliasmith and Clark are right - and maybe such Earthly animals are all they really have in view. But as a universal principle, insistence on high bandwidth synchrony seems unmotivated. From a cosmological perspective, it's hard to see why speed per se should matter. Couldn't conscious intelligence be slow-paced, especially in large entities? And it's hard to see why synchrony should matter either, as long as the functional tasks necessary for intelligent responsiveness are successfully executed. Is there good reason to think, for example, that consciousness would necessarily be absent in a large slow-paced alien whose cognition involved transfer delays between its subprocesses?

Fred Dretske, in correspondence, has suggested that the U.S. could not be conscious because its representational states depend on the conscious states of others. Such dependence, he

themselves in personal communication. (See the comments section of Schwitzgebel 2012c for Humphrey, below for Dretske and Dennett, and Section 2 for Tononi.) 
says, renders its representations conventional rather than natural - and a conscious entity must have natural representations. ${ }^{22}$

In earlier work, Dretske (1995) highlights the implausibility of supposing that an object that has no intrinsic representational functions can become conscious simply because outside users impose representational functions upon it. We don't make a mercury column conscious by calling it a thermometer, nor do we make a machine conscious by calling it a robot and interpreting its outputs as speech acts. The machine either is or is not conscious, it seems, independently of our intentions and labels. A wide range of materialists, I suspect, will and should accept that an entity cannot be conscious if all its representations depend in this way on external agents. Focusing on such cases, Dretske's independency criterion seems appealing.

But the citizens and residents of the United States are parts of the U.S. rather than external agents, and it's not clear that the dependency of consciousness on the intentions and purposes of internal agents is problematic in the same way, if the internal agents' behavior is properly integrated with the whole. The internal and external cases are sufficiently dissimilar that before accepting Dretske's principle in general form it seems we should at least consider some potential internal-agent cases. And indeed Ringworld and Antares seem to give us such cases. Furthermore, although Dretske's criterion is not exactly an anti-nesting principle in the sense of Section 2, it is subject to the same concerns. In its broad form it seems unmotivated, except by a desire to exclude the types of case in dispute; it seems improperly to exclude the Antareans, at least on the assumption that the individual Antarean ants are "others" in the relevant sense; and it brings new counterintuitive consequences in its train, such as loss of

${ }^{22}$ In earlier published work, Dretske says that a representation is natural if it is not "derived from the intentions and purposes of its designers, builders, and users" (1995, p. 7) rather than the more general criterion, above, of independency from "others". In light of our correspondence on group consciousness, he says that he has modified this aspect of his view. 
consciousness upon inhaling Planck-scale people whose actions are smoothly incorporated into one's brain functions. On Dretske's proposed principle, as on the anti-nesting principles discussed in Section 2, entities that behave identically on a large scale and have superficially similar evolutionary and developmental histories might either have or lack consciousness depending on micro-level differences that are seemingly unreportable (to them), unintrospectible (to them), unrelated to their opinions about Proust, and thus, it seems natural to suppose, irrelevant.

Dretske conceptualizes his criterion as dividing "natural” representations from "conventional" or artificial ones. Maybe it is reasonable to insist that a conscious being have natural representations. But from a telescopic perspective national groups and their representational activities are eminently natural - as natural as the structures and activities of groups of cells clustered into spatially contiguous individual organisms. What should matter on a broadly Dretskean approach, I'm inclined to think, is that the representational functions emerge naturally from within rather than being imposed artificially from outside, and that they are properly ascribed to the entity as a whole rather than only to a subpart. Both Antarean opinions about Shakespeare and the official U.S. position on Iran's nuclear program meet these criteria.

Daniel Dennett, in correspondence, offers a pragmatic objection: To the extent the United States is radically unlike individual human beings, it's unhelpful to ascribe consciousness to it. Its behavior is impoverished compared to ours and its functional architecture is radically unlike our own. Ascribing consciousness to the United States is not so much straightforwardly false, Dennett suggests, as it is pragmatically misleading, inviting the reader to too closely assimilate human architecture and group architecture. 
To this objection I respond, first, that the United States is not behaviorally impoverished. It does lots of things, as described in Sections 4 and 5 above - probably more than any individual human does. (In this way it differs from the aggregate of the U.S., Germany, and South Africa, and probably also from the aggregate of all of humanity.) Second, to hang the metaphysics of consciousness on specific details of architecture runs counter to the spirit that admits the Sirians and Antareans to the realm of beings who would (hypothetically) be conscious. Thus it risks collapsing into neurochauvinism (Section 7 below). And third, we can presumably dodge any practical worries about leaping to assimilative inferences by being restrained in our inferences. We can refrain from assuming, for example, that when the U.S. is angry its anger is felt, phenomenologically, as anything like the anger of individual human beings; we can even insist that "anger" is not a great word and simply the best we can do with existing language. The U.S. can't feel blood rush to its head; it can't feel tension in its arms; it can't "see red". It can muster its armies, denounce the offender via spokespeople in Security Council meetings, and enforce an embargo. What it feels like, if anything, to enforce an embargo, defenders of U.S. consciousness can wisely refrain from claiming to know.

Riffling through existing theories of consciousness, we could try to find, or we could invent, some metaphysically necessary condition for consciousness that human beings meet that the United States fails to meet. I don't doubt that a clever criterion could be found that would include human beings, exclude the United States, and include at least some of the more plausible non-human entities. Perhaps, then, the most conservative reading of my argument is as a challenge: Let's try to find a criterion that delivers this appealing conclusion! But I worry, first, that this is suspiciously post-hoc, and second, that it lacks the kind of elegant simplicity of a 
materialism that treats Earthly rabbits, Sirian squidbits, Antarean antheads, and the United States all as on a par due to their broad behavioral and functional similarities.

Alternatively, some readers - perhaps especially empirically-oriented readers - might suggest that my argument does little other than to display the bankruptcy of metaphysical speculation about bizarre cases. How could we really know whether Antarean antheads, assuming them possible, would really be conscious? How could we hope to build any serious theory on science fictional intuitions? I sympathize with this reaction. Perhaps we should abandon any aspiration for a truly universal metaphysics that would cover the whole range of bizarre possibilities. But that reaction wouldn't give us much guidance about the question of U.S. consciousness, if we are suspicious enough of common sense to think that our commonsensical reaction does not decisively settle the question. Despite my sympathies with skepticism about the metaphysics of bizarre cases, I want, and I think it's reasonable to want, at least a conditional assessment or best guess about whether we are parts of a larger conscious organism, and I see no better way to try to reach such a tentative assessment.

\section{Three Ways Out.}

Let's briefly consider more conservative views about the distribution of consciousness in the universe, to see if they can provide a suitable exit from the bizarre conclusion that the United States is literally conscious.

Eliminativism. Maybe the United States isn't conscious because nobody is conscious not you, not me, not rabbits, not aliens. Maybe "consciousness" is such a corrupt, broken concept, embedded in such a radically false worldview, that we should discard it entirely, as we discarded the concepts of demonic possession, the luminiferous ether, and the fates. 
In this essay, I have tried to use the concept of consciousness in a plain way, unadorned with dubious commitments like irreducibility, immateriality, and infallible self-knowledge. Maybe I have not succeeded, but then I hope you will permit me to rephrase my claim: Whatever it is about us in virtue of which we are tempted to say human beings and rabbits have conscious experience or phenomenology, the United States has that same thing.

The most visible philosophical eliminativists about terms from folk psychology still seem to have room in their theories for consciousness, suitably stripped of dubious commitments. ${ }^{23}$ So if you tread this path, you're going farther than they. In fact, Paul Churchland (1984/1988) says several things that seem, jointly, to commit him to accepting the idea that cities or countries would be conscious (though he doesn't to my knowledge explicitly draw the conclusion). ${ }^{24}$

Galen Strawson says that denying the existence of conscious experience is "the strangest thing that has ever happened in the whole history of human thought" (2006, p. 5). This underestimates, I suspect, the strangeness of religion; but still, radical eliminativism seems at least as strange as believing that the United States is conscious.

Extreme sparseness. Here's another way out for the materialist: Argue that consciousness is rare, so that really only very specific types of systems possess it, and then argue that the United States does not meet the restrictive criteria. If the criteria are specifically neural criteria, this position is a form of neurochauvinism, which I will discuss shortly. Setting aside

${ }^{23}$ For example, P.M. Churchland 1984/1988; P.S. Churchland 2002; Stich 2009. Contrast skepticism about loaded versions of "consciousness" or "qualia" in P.S. Churchland 1983 and Dennett 1991.

${ }^{24}$ Churchland characterizes as a living being "any semiclosed system that exploits the order it already possesses, and the energy flux through it, in such a way as to maintain and/or increase its internal order" (1984/1988, p. 173). By this definition, Churchland suggests, beehives, cities, and the entire biosphere all qualify as living beings (ibid.). Consciousness and intelligence, Churchland further suggests, are simply sophistications of this basic pattern - cases in which the semiclosed system exploits energy to increase the information it contains, including information about its own internal states and processes (1984/1988, p. 173 and 178). 
neurochauvinism, the most commonly endorsed version of the extreme sparseness view is one in which language is required for consciousness. ${ }^{25}$ Thus, dogs, wild apes, and human infants aren't conscious; maybe neither are certain deaf-mute or extremely aphasic adults. On this view, there is nothing it's like to be such beings, any more than there is something it's like (most people think) to be a diode or a fleck of dust. To a dog, all is dark inside, or rather, not even dark. This view is both radically counterintuitive and, I'd suggest, a gross overestimation of the gulf between us and our nearest relatives.

However, it's not clear that we get to exclude the consciousness of the United States by restricting consciousness to beings with language, since the United States does seemingly speak as a collective entity, as I've mentioned. Its linguistic behavior, interpreted as such by other nations, influences the behavior, both linguistic and non-linguistic, of those other nations. If the materialist is to deny U.S. consciousness on the grounds of general commitment to the sparseness of consciousness in the universe, then even more severe restrictions are required, or at least different ones. Perhaps phenomenal consciousness requires the ability to self-report the existence of phenomenal consciousness? Then even four-year-olds might not have it. This seems a tough road. ${ }^{26}$

Neurochauvinism. A third way out is to assume that consciousness requires neurons neurons clumped together in the right way, communicating by ion channels and all that, rather than by voice and gesture. All the entities that we have actually met and that we normally think of as conscious do have their neurons bundled in that way, and the $3 \times 10^{19}$ neurons of the United

${ }^{25}$ This view is famously espoused by Descartes (1649/1991). Carruthers $(1996,1998)$ has recently defended the view from a materialist perspective. See also Dennett's qualms in his 1996 and 1998. For a review of the issues, see Allen 1995/2010.

${ }^{26}$ A road trodden, perhaps, in Jaynes 1976. 
States are not as a whole bundled in that way. So maybe by identifying consciousness with certain types of neural states, we can legitimately rule out U.S. consciousness.

This view gains intuitive support through examples from Ned Block (1978/1991) and John Searle $(1980,1984)$. Suppose we arranged the people of China into a giant communicative network resembling the functional network instantiated by the human brain. It would be absurd, Block says, to regard such an entity as conscious (though see Lycan 1981). Similarly, Searle asserts that no arrangement of beer cans, wires, and windmills, no matter how cleverly set up, could ever house a genuine stream of conscious experience (though see Cuda 1985). According to Block and Searle, what these entities are lacking isn't a matter of large-scale functional structure of the sort that reveals itself in patterns of input-output relations. Consciousness requires not that, or not only that; consciousness requires human biology.

Or rather, consciousness, on this view, requires something like human biology. In what way like? Here Block and Searle aren't very helpful. According to Searle, for example, “any system capable of causing consciousness must be capable of duplicating the causal powers of the brain" (1992, p. 92). In principle, Searle suggests, this could be done by completely different physical mechanisms. But what mechanisms could do this and what mechanisms could not, Searle makes no attempt to adjudicate, other than by excluding certain systems, like beer-can systems, as plainly the wrong sort of thing. Instead, Searle gestures hopefully at future science.

The reason for not strictly insisting on neurons, I suspect, is this: If we're playing the intuition game, that is, if counterintuitiveness is our reason for excluding beer-can systems and organized groups of people, then we're going to have to allow the possibility, at least in principle, of conscious beings from other planets who operate other than by neural systems like 
our own. That's because our armchair intuitions tell us that some such beings could be conscious despite lacking neurons.

From a cosmological perspective it would be strange to suppose that of all the possible beings in the universe that are capable of sophisticated, self-preserving, goal-directed environmental responsiveness, beings that could presumably be (and in a vast enough universe presumably actually are) constructed in myriad strange and diverse ways, somehow only we with our neurons have genuine conscious experience, and all others are mere automata there is nothing it is like anything to be. Contrary to the "Copernican Principle" of cosmological method, ${ }^{27}$ this view would suggest that we, as the sole possessors of consciousness, are in a uniquely favored position in the universe. How lucky we are! (The other beings, I suppose, only say they're lucky, or only emit noises that we would mistakenly regard as having that semantic content. $^{28}$ ) For this reason, it seems not only unintuitive but also scientifically unjustified to suppose that conscious experience requires Earthly biology. It would be like supposing that life requires Earthly nucleotides.

If they're to avoid un-Copernican neuro-fetishism, the question must become, for Block and Searle, what feature of neurons, possibly possessed also by non-neural systems, gives rise to consciousness? In other words, we are back with the question of Section 5 - that is, with the question of what is so special about brains - and the only well-developed answers on the near horizon seem to involve appeals to the sorts of features that the United States has, features like massively complex informational integration, self-monitoring, and a long-standing history of sophisticated environmental responsiveness.

${ }^{27}$ Bondi 1952/1968; Beisbart and Jung 2006.

${ }^{28}$ Wait. Are we those other non-conscious beings? See the treatment of "zombies" in Chalmers 1996; Dretske 2003; Weisberg 2011. 
This view, then, faces a dilemma. Either appeal to the types of features that seem the most plausible material features of conscious neural systems, thereby letting in the Sirians and the Antareans and probably also the United States, or fall into an extreme neurochauvinism that, by excluding aliens, jettisons both the Copernican Principle and the types of intuition preservation that seem to be at the foundation of the neurochauvinist's own argument. If there is a path between these two horns, it remains almost entirely uncharted.

\section{Conclusion.}

In sum, the argument is this: There seems to be no principled reason to deny entityhood, or entityhood-enough, to spatially distributed but informationally integrated beings. So the United States is at least a candidate for the literal possession of real psychological states, including consciousness. Once we view the United States in this way, the question then becomes whether it meets plausible materialistic criteria for consciousness. My suggestion is that if those criteria are liberal enough to include both small mammals and alien species that exhibit sophisticated linguistic behavior, then the United States probably does meet those criteria. The United States is massively informationally interconnected and responds in sophisticated, goaldirected ways to its surroundings. Its internal representational states are functionally responsive to its environment and not randomly formed or assigned artificially from outside by the acts of an external user. And the United States exhibits complex linguistic behavior, including issuing self-reports and self-critiques that reveal a highly-developed ability to monitor its evolving internal and external conditions. In light of such considerations, I find myself drawn to think that the materialist probably ought to accept, at least tentatively, that the United States is conscious. 
But that conclusion seems so absurdly bizarre! Now, if our sense of bizarreness were a good index of reality in fundamental matters about the physical and metaphysical structure of the universe, that would be good reason to reject the conclusion. But even a passing glance at contemporary physics and metaphysics suggests that common sense is no sure guide at all (a point I develop farther in Schwitzgebel in draft). Large things are hard to see properly when you're in their midst. The homunculi in your head, the tourist in Leibniz's mill, they don't see consciousness either. ${ }^{29}$ Too vivid an appreciation of the local mechanisms overwhelms their view. The space between us is an airy synapse.

If the United States is conscious, is Exxon-Mobil? Is an aircraft carrier? $?^{30}$ Is the seven dwarfs of Snow White? Where does it end? And if such entities are conscious, do they have rights? Is dissolution murder? The United States doesn't seem to think of itself as a conscious being, but might that change if enough people adopt the perspective of this essay? I'm not sure whether I have provided grounds for believing the U.S. is conscious, or instead a challenge to materialist theories of consciousness, or instead reasons to be wary in general of ambitions toward a universal metaphysics of mind. Whoops, I hear someone knocking on my office door.... ${ }^{31}$

${ }^{29}$ On the homunculi, see for example Fodor 1968. Leibniz imagines entering into a vastly enlarged brain as into a mill in his 1714/1989.

${ }^{30}$ See Hutchins 1995 for a vivid portrayal of distributed cognition in military vessels. I don't know if he would embrace similarly distributed phenomenal consciousness, however.

${ }^{31}$ For helpful discussion of these issues in the course of writing, thanks to Santiago Arango, Scott Bakker, Zachary Barnett, Mark Biswas, Ned Block, Dan Dennett, Fred Dretske, Louie Favela, Kirk Gable, Chris Hill, Linus Huang, Nick Humphrey, Bill Lycan, Pete Mandik, Tori McGeer, Luke Roelofs, Giulio Tononi, Vernor Vinge, and Rob Wilson; to audiences at University of Cincinnati, Princeton University, and Bob Richardson's seminar on extended cognition; and to the many readers who posted comments on relevant posts on my blog, The Splintered Mind. My wife Pauline worries that I am too passionate in defending the rights of antheads who, she says, don't even really exist. My thirteen-year-old son Davy, however, thinks that for the first time in my career I'm now actually writing about something interesting. 


\section{$\underline{\text { References: }}$}

Allen, Colin (1995/2010). Animal consciousness. Stanford Encyclopedia of Philosophy (Winter 2011 edition).

Arico, Adam (2010). Folk psychology, consciousness, and context effects. Review of Philosophy and Psychology, 1, 371-393.

Averroës (Ibn Rushd) (12 $2^{\text {th }}$ c./2009). Long commentary on the De Anima of Aristotle, trans. R.C. Taylor. New Haven: Yale.

Baars, Bernard J. (1988). A cognitive theory of consciousness. Cambridge: Cambridge.

Balduzzi, David, and Giulio Tononi (2009). Qualia: The geometry of integrated information. PLoS Computational Biology, 5: 8 .

Beisbart, Claus, and Tobias Jung (2006). Privileged, typical, or not even that? Our place in the world according to the Copernican and Cosmological Principles. Journal for General Philosophy of Science, 37, 225-256.

Bettencourt, B. Ann, Marilynn B. Brewer, Marian Rogers Croak, and Normal Miller (1992). Cooperation and the reduction of intergroup bias: The role of reward structure and social orientation. Journal of Experimental Social Psychology, 28, 301-319.

Block, Ned (1978/1991). Troubles with functionalism. In The nature of mind, ed. D.M. Rosenthal. Oxford: Oxford..

Block, Ned (2002). The harder problem of consciousness. Journal of Philosophy, 99, 391-425. Bondi, Herman (1952/1968). Cosmology, $2^{\text {nd }}$ ed. Cambridge: Cambridge.

Bratman, Michael (1999). Faces of intention. Cambridge: Cambridge.

Burge, Tyler (1979). Individualism and the mental. Midwest Studies in Philosophy, 4, 73-122. Burge, Tyler (2010). Origins of objectivity. Oxford: Oxford. 
Carey, Susan (2009). The origin of concepts. Oxford: Oxford.

Carruthers, Peter (1996). Language, thought and consciousness. Cambridge: Cambridge.

Carruthers, Peter (1998). Animal subjectivity. Psyche, 4: 3.

Carruthers, Peter (2001/2011). Higher-order theories of consciousness. Stanford Encyclopedia of Philosophy (Fall 2011 edition).

Chalmers, David J. (1996). The conscious mind. Oxford: Oxford.

Chomsky, Noam (2009). The mysteries of nature: How deeply hidden? Journal of Philosophy, $106,167-200$.

Churchland, Patricia S. (1983). Consciousness: The transmutation of a concept. Pacific Philosophical Quarterly, 64, 80-95.

Churchland, Patricia S. (2002). Brain-wise. Cambridge, MA: MIT.

Churchland, Paul M. (1981). Eliminative materialism and the propositional attitudes. Journal of Philosophy, 78, 67-90.

Churchland, Paul M. (1984/1988). Matter and consciousness, rev. ed. Cambridge, MA: MIT.

Churchland, Paul M. (1984/1988). Matter and consciousness, rev. ed. Cambridge, MA: MIT.

Cisco Corporation (2012). Cisco visual networking index: Forecast and methodology, 20112016. Available at: http://www.cisco.com/en/US/solutions/collateral/ns341/ns525/ns537/ns705/ns827/white_ paper_c11-481360.pdf (accessed June 1, 2012).

Clark, Andy (2009). Spreading the joy? Why the machinery of consciousness is (probably) still in the head. Mind, 118, 963-993.

Clark, Austen (1994). Beliefs and desires incorporated. Journal of Philosophy, 91, 404-425. Crick, Francis (1994). The astonishing hypothesis. New York: Charles Scribner's Sons. 
Cuda, Tom (1985). Against neural chauvinism. Philosophical Studies, 48, 111-127.

Davidson, Donald (1987). Knowing One's Own Mind, Proceedings and Addresses of the American Philosophical Association, 61, 441-58.

Dennett, Daniel C. (1991). Consciousness explained. Boston: Little, Brown, and Company.

Dennett, Daniel C. (1996). Kinds of minds. New York: BasicBooks.

Dennett, Daniel C. (1998). Brainchildren. Cambridge, MA: MIT.

Dennett, Daniel C. (2005). Sweet dreams. Cambridge, MA: MIT.

Descartes, René (1649/1991). Letter to More, 5 Feb. 1649. In The philosophical writings of

Descartes, vol. 3, ed. J. Cottingham, R. Stoothoff, D. Murdoch, and A. Kenny. Cambridge: Cambridge.

Dretske, Fred (1988). Explaining behavior. Cambridge, MA: MIT.

Dretske, Fred (1995). Naturalizing the mind. Cambridge, MA: MIT.

Dretske, Fred (2003). How do you know you are not a zombie? In Privileged access, ed. B. Gertler. Aldershot, England: Ashgate.

Edelman, Shimon (2008). Computing the mind. Oxford: Oxford.

Elder, Crawford (2011). Familiar objects and their shadows. Cambridge: Cambridge.

Eliasmith, Chris (2009). Dynamics, control, and cognition. In Cambridge handbook of situated cognition, P. Robbins and M. Aydede, eds. Cambridge: Cambridge.

Espinas, Alfred (1877/1924). Des sociétés animales, $3^{\text {rd }}$ ed. Paris: Félix Alcan.

Fodor, Jerry A. (1968). The appeal to tacit knowledge in psychological explanation. Journal of Philosophy, 65, 627-640.

Gendler, Tamar Szabó (2008a). Alief and belief. Journal of Philosophy, 105, 634-663.

Gendler, Tamar Szabó (2008b). Alief in action, and reaction. Mind \& Language, 23, 552-585. 
Gilbert, Margaret (1989). On social facts. Princeton, NJ: Princeton.

Godfrey-Smith, Peter (2009). Darwinian populations and natural selection. Oxford: Oxford.

Gopnik, Alison, and Eric Schwitzgebel (1998). Whose concepts are they, anyway? The role of philosophical intuition in empirical psychology. In Rethinking intuition, ed. M.R. DePaul and W. Ramsey. Lanham: Rowman and Littlefield.

Greene, Brian (2011). The hidden reality. New York: Vintage.

Haslanger, Sally (2008). Changing the ideology and culture of philosophy: Not by reason (alone). Hypatia, 23, 210-22.

Hilbert, Martin, and Priscila López (2011). The world's technological capacity to store, communicate, and compute information. Science, 332, 60-65.

Hill, Christopher S. (1991). Sensations. Cambridge: Cambridge.

Hill, Christopher S. (2009). Consciousness. Cambridge: Cambridge.

Huebner, Bryce (forthcoming). Macrocognition. Oxford: Oxford

Huebner, Bryce, Michael Bruno, and Hagop Sarkissian (2010). What does the nation of China think about phenomenal states? Review of Philosophy and Psychology, 1, 225-243.

Hume, David (1740/1978). A treatise of human nature, ed. L.A. Selby-Bigge and P.H. Nidditch. Oxford: Oxford.

Hurley, Susan (1998). Consciousness in action. Cambridge, MA: Harvard.

Hutchins, Edwin (1995). Cognition in the wild. Cambridge, MA: MIT.

Jaynes, Julian (1976). The origin of consciousness in the breakdown of the bicameral mind. Boston: Houghton Mifflin.

Kant, Immanuel (1781/1787/1998). Critique of pure reason, ed. and trans. P. Guyer and A.W. Wood. Cambridge: Cambridge. 
Knobe, Joshua, and Jesse Prinz (2008). Intuitions about consciousness: Experimental studies. Phenomenology and the Cognitive Sciences, 7, 67-83.

Korman, Daniel (2011). Ordinary objects. Stanford Encyclopedia of Philosophy (Winter 2011 edition).

Kornblith, Hilary (1998). The role of intuition in philosophical inquiry: An account with no unnatural ingredients. In Rethinking intuition, ed. M.R. DePaul and W. Ramsey. Lanham: Rowman and Littlefield.

Kurzweil, Ray (2005). The singularity is near. New York: Penguin.

Ladyman, James, and Don Ross (2007). Every thing must go. Oxford: Oxford.

Leibniz, G.W. (1714/1989). The principles of philosophy, or, the monadology. In Philosophical Essays, ed. and trans. R. Ariew and D. Garber. Indianapolis: Hackett.

Lewis. David K. (1980). Mad pain and Martian pain. In Readings in philosophy of psychology, ed. N. Block. Cambridge, MA: Harvard.

List, Christian, and Philip Pettit (2011). Group agency. Oxford: Oxford.

Lycan, William G. (1981). Form, function, and feel. Journal of Philosophy, 78, 24-50.

Mandik, Pete, and Josh Weisberg (2008). Type Q materialism. In Naturalism, reference, and ontology, ed. C.B. Wrenn. New York: Peter Lang.

Maynard Smith, John, and Eors Szathmáry (1995). The major transitions in evolution. Oxford: Oxford.

McDougall, William (1920). The group mind. New York: Putnam.

Metzinger, Thomas (2003). Being no one. Cambridge, MA: MIT.

Millikan, Ruth Garrett (1984). Language, thought, and other biological categories. Cambridge, MA: MIT. 
Millikan, Ruth Garrett (2010). On knowing the meaning: With a coda on Swampman. Mind, 119, 43-81.

Montero, Barbara (1999). The body problem. Noûs, 33, 183-200.

Moravec, Hans (1997). When will computer hardware match the human brain? Available at http://www.transhumanist.com/volume1/moravec.htm (accessed June 1, 2012).

Niven, Larry (1970). Ringworld. New York: Random House.

Noë, Alva (2004). Action in perception. Cambridge, MA: MIT.

Parfit, Derek (1984). Reasons and persons. Oxford: Oxford.

Petty, Richard E., Russell H. Fazio, and Pablo Briñol, eds. (2009). Attitudes: Insights from the new implicit measures. New York: Taylor and Francis.

Phelan, Mark, Adam Arico, and Shaun Nichols (forthcoming). Thinking things and feeling things: On an alleged discontinuity in folk metaphysics of mind.

Polger, Thomas W. (2004). Natural minds. Cambridge, MA: MIT.

Putnam, Hilary (1965). Psychological predicates. In Art, mind, and religion, ed. W.H. Capitan \& D.D. Merrill. Liverpool: University of Pittsburgh Press / C. Tinling.

Putnam, Hilary (1975). Mind, language and reality. London: Cambridge.

Rockwell, Teed (2005). Neither brain nor ghost. Cambridge, MA: MIT.

Rupert, R. (2005). Minding one's own cognitive system: When is a group of minds a single cognitive unit? Episteme, 1, 177-88.

Ryle, Gilbert (1949). The concept of mind. New York: Barnes \& Noble.

Schäffle, Albert E. F. (1896). Bau und Leben des socialen Körpers, $2^{\text {nd }}$ ed. Tübingen: Laupp'schen. 
Scholl, Brian (2007). Object persistence in philosophy and psychology. Mind \& Language, 22, 563-591.

Schwitzgebel, Eric (2010). Acting contrary to our professed beliefs, or the gulf between occurrent judgment and dispositional belief. Pacific Philosophical Quarterly, 91, 531553.

Schwitzgebel, Eric (2011). Knowing your own beliefs. Canadian Journal of Philosophy, 35, supplement, 41-62.

Schwitzgebel, Eric (2012a). Why Dennett should think that the United States is conscious. Blog post at The Splintered Mind (http://schwitzsplinters.blogspot.com), Feb. 9, 2012.

Schwitzgebel, Eric (2012b). Why Dretske should think that the United States is conscious. Blog post at The Splintered Mind (http://schwitzsplinters.blogspot.com), Feb. 17, 2012.

Schwitzgebel, Eric (2012c). Why Humphrey should think that the United States is conscious. Blog post at The Splintered Mind (http://schwitzsplinters.blogspot.com), Mar. 8, 2012. Schwitzgebel, Eric (2012d). Why Tononi should think that the United States is conscious. Blog post at The Splintered Mind (http://schwitzsplinters.blogspot.com), Mar. 23, 2012.

Schwitzgebel, Eric (2012e). Why Tononi should allow that conscious entities can have conscious parts. Blog post at The Splintered Mind (http://schwitzsplinters.blogspot.com), June 6, 2012.

Schwitzgebel, Eric (in draft). The crazyist metaphysics of mind. Available at http://faculty.ucr.edu/ eschwitz

Searle, John (1980). Minds, brains, and programs. Behavioral and Brain Sciences, 3, 417-457. Searle, John (1984). Minds, brains, and science. Cambridge, MA: Harvard. Searle, John (1992). The rediscovery of the mind. Cambridge, MA: MIT. 
Searle, John (2010). Making the social world. Oxford: Oxford.

Sober, Elliott, and David Sloan Wilson (1998). Unto others. Cambridge, MA: Harvard.

Spelke, Elizabeth S., Karen Breinlinger, Janet Macomber, and Kristen Jacobson (1992). Origins of knowledge. Psychological Review, 99, 605-632.

Stich, Stephen (1983). From folk psychology to cognitive science. Cambridge, MA: MIT.

Stich, Stephen (2009). Five answers. In Mind and consciousness, ed. S. Grim. Automatic Press.

Stock, Gregory (1993). Metaman. Toronto: Doubleday Canada.

Stoljar, Daniel (2010). Physicalism. Oxford: Routledge.

Strawson, Galen (2006). Consciousness and its place in nature. Exeter: Imprint Academic.

Strawson, P.F. (1959). Individuals. London: Methuen.

Sytsma, Justin M., and Edouard Machery (2010). Two conceptions of subjective experience. Philosophical Studies, 151, 299-327.

Teilhard de Chardin, Pierre (1955/1965). The phenomenon of man, rev. English ed., trans. B. Wall. New York: Harper \& Row.

Tononi, Giulio (2004). An information integration theory of consciousness. BMC Neuroscience, 5: 42 .

Tononi, Giulio (2008). Consciousness as integrated information: A provisional manifesto. Biological Bulletin, 215, 216-242.

Tononi, Giulio (2010). Information integration: Its relevance to brain function and consciousness. Archives Italiennes de Biologie, 148, 299-322.

Tononi, Giulio (2012). Phi. New York: Pantheon.

Tononi, Giulio (forthcoming). The integrated information theory of consciousness: An updated account. Archives Italiennes de Biologie. 
Tuomela, Raimo (2007). The philosophy of sociality. Oxford: Oxford.

Turing, A.M. (1950). Computing machinery and intelligence. Mind, 59, 433-460.

Vinge, Vernor (1992). A fire upon the deep. New York: Tor.

Vinge, Vernor (2011). Children of the sky. New York: Tor.

Wason, P.C. (1968). Reasoning about a rule. Quarterly Journal of Experimental Psychology, $20,273-281$.

Weinberg, Jonathan M., Chad Gonnerman, Cameron Buckner, and Joshua Alexander (2010). Are philosophers expert intuiters? Philosophical Psychology, 23, 331-355.

Weisberg, Josh (2011). The zombie's cogito: Meditations on type-Q materialism. Philosophical Psychology, 24, 585-605.

Wilson, Jack (1999). Biological individuality. Cambridge: Cambridge.

Wilson, Robert A. (2004). Boundaries of the mind. Cambridge: Cambridge.

Wilson, Robert A. (2005). Genes and the agents of life. Cambridge: Cambridge.

Wittenbrink, Bernd, and Norbert Schwarz, eds. (2007). Implicit measures of attitudes. New York: Guilford.

Wundt, Wilhelm (1897/1897). Outlines of psychology, trans. C. H. Judd. Leipzig: Wilhelm Engelmann. 